\title{
Reincarnation, Predestination and Moral Responsibility: Critical Issues in Akan Philosophy
}

\author{
H.M. Majeed \\ Department of Philosophy and Classics \\ University of Ghana \\ mmajeed50@yahoo.com OR mmajeed@ug.edu.gh
}

DOI: http://dx.doi.org/10.4314/tp.v7i2.6

Thought and Practice: A Journal of the Philosophical Association of Kenya (PAK)

New Series, Vol.7 No.2, December 2015, pp.105-122

thoughtandpractice@gmail.com

http://ajol.info/index.php/tp

ISSN: 2076-7714 


\begin{abstract}
African scholars such as Bolaji Idowu and John Mbiti have argued that belief in reincarnation is alien to African thought. However, this article argues that an adequate understanding of the Ghanaian Akan culture points to the presence of reincarnation in Akan, and for that matter African, philosophy. Nevertheless, unlike in Indian philosophy, for instance, where reincarnation depends on the quality of an individual's moral life and is a means of ensuring moral responsibility, in Akan philosophy reincarnation is not dependent on moral considerations. Yet there is the idea of moral responsibility in Akan philosophy. The article interrogates how moral responsibility, an idea which is ordinarily regarded as reasonable in the presence of free will, is in the case of the Akan held alongside predestination. The article also reveals some serious philosophical difficulties which this Akan conception of moral responsibility generates in respect of the 'reincarnated' person.
\end{abstract}

\title{
Keywords
}

Reincarnation, predestination, moral responsibility, Akan philosophy, immortality, dualism, life and death

\section{Introduction}

The concepts of reincarnation, predestination and moral responsibility are made to constitute the title of this article because of the apparent logical link that exists among them, and the fact that they appear to generate complex problems of philosophical interest. Reincarnation is the belief that a person who is physically dead can again be born to live here on earth (Aurobindo 1999, 234). Predestination could mean the prior determination of actions or events in the world by fate (or destiny) or by divine foreordination. In philosophy of religion, the question of predestination is, to a large extent, ultimately examined at the level of the human being, whereby through predestination, a person's condition of life, or events in a person's life are believed to be determined or fixed in advance. 
For all intents and purposes, predestination suggests some absence of human free will. The human being is one of the ontological categories found in Akan philosophy. According to Kwame Gyekye, these beings, in order of potency, consist of God, the deities, the revered-dead, human beings and natural objects (Gyekye 1995, 75). While reincarnation, predestination and moral responsibility could be understood in terms of the human being, they have something to do with the other beings as well. For instance, in Akan philosophy, it is believed that the revered-dead may reincarnate, that God is the architect of human destiny, and that the revered-dead, the deities or God may hold a person accountable for his or her actions.

In several places in this work, I mention Indian culture, Indian philosophy or the Indian conception of reincarnation. I do so for the purpose of comparison. Although this article is on Akan (which is an African) culture, I do not always compare Akan beliefs with other African beliefs. I discuss Akan beliefs in connection with Indian ones because of the striking difference between the two. For instance, there is the belief in the necessity of reincarnation on purely moral grounds in Indian philosophical thought, a belief which the Akan (and probably many other African peoples) do not hold. In Indian thought, a person's moral life determines how he or she reincarnates, and reincarnation, unlike in Akan philosophy, also ensures that each person is morally held accountable in his or her next life.

However, the notion of moral responsibility is philosophically linked to the concept of determinism (or predestination, more or less) because the rationality of moral responsibility is predicated on the principle that the human being acts freely. Nevertheless, free will appears inconsistent with the idea of predestination. It is worth noting that in the Akan conceptual framework, while moral responsibility is affirmed, there is also belief in some form of predestination, ${ }^{1}$ so that these two concepts are not considered to be mutually exclusive. A person's moral choices, for instance, are freely made (and not determined) whether or not one is believed to be reincarnated. Therefore the doctrines of predestination and free will, which are key religious beliefs, have philosophical underpinnings. Besides, just like reincarnation, they are objects of philosophical reflection.

\footnotetext{
${ }^{1}$ I do not suggest that Indian philosophy may not have a position similar to this.
} 
Reincarnation suggests a continuation of an individual (and, sometimes, of his or her life pattern or goals) in a future existence. However, this suggestion entails logical and practical problems, such as how actions in two separate lives could practically belong to the same person; and how, if that is possible, the alleged reincarnated person could be held responsible for the actions performed by him or her in the previous life. If he or she cannot be held responsible this way, how justifiable would it be to claim that: first, a person really comes back into the world to continue a life; and, second, the principle that a person must always be held responsible for his or her actions ought to be upheld? I argue in this article that the Akan conceptions of reincarnation and moral responsibility suffer this confusion and cannot be consistently held.

Belief in reincarnation presupposes belief in the capacity of the human being or, to be more specific, part of the human being to live beyond death. In many cultures and religions across the world in which reincarnation is postulated - such as the African cultures of Chagga, Lodagaa and Ga (Mbiti 1989, 155), ${ }^{2}$ the ancient Greeks (Republic, Bk 10), Hindus (Kamath 2008, 68-70) and Incas (Cobo 1990, 19) - there seems to be a projection of the philosophical concept of dualism, that is, the idea that a person has two different but inter-dependent parts, namely, body and soul, and that the body perishes at death but the soul survives death. This idea is, in Western thought, very much associated with Plato (Phaedo) and Descartes (1962).

Belief in the duality of persons is also found in Akan philosophy, where nipadua (body) and $\overline{o k r a}$ (soul) are distinguished. However, the $\overline{o k r a}$, in addition to its being invisible, is believed to contain another invisible entity called sunsum (spirit) (Gyekye 1995, 98). Nevertheless, not all Akan philosophers understand sunsum and ōkra in invisible terms. Kwasi Wiredu (1983, 120) and Safro Kwame (2004, 345-346) think that the two entities are rather 'quasi-physical'. Yet what all these philosophers appear to have in common is the understanding that Akan thinkers conceive of the $\overline{o k r a}$ as immortal. Gyekye $(1995,98)$ mentions in passing that the Akan belief in the soul's immortality provides for the possibility of reincarnation - and this is a view that I

\footnotetext{
${ }^{2}$ Although Mbiti reports these peoples as purporting to believe in reincarnation, his own analysis within the broad framework of African cultural beliefs leads him to the conclusion that there is really no belief in reincarnation as such in African thought (Mbiti 1989, 83).
} 
share and seek to defend in this work. The point is that in the Akan context where human survival takes the form of the soul, only it (the soul) can logically be associated with post-mortem 'human' activity or manifestation.

In this article, I explore whether or not reincarnation in Akan thought is driven by some conditions - conditions that necessitate its occurrence - and the extent to which the life of a person believed to have reincarnated is influenced by such a necessity. The purpose of this undertaking is to help explain the concept of predestination in relation to reincarnation, and the extent to which an alleged reincarnated person could be morally held responsible.

\section{Reincarnation in Akan Philosophical Thought}

Some prominent African scholars including Bolaji Idowu (1963, 187) and John Mbiti (1989, 83) have argued strongly against the possible presence of belief in reincarnation in African philosophical thought. They suggest that spirits of the revered dead (or 'the living-dead', to adopt Mbiti's description) are believed, in African ontology of invisible beings, to live permanently in the world of spirits; and, as a result, cannot be said to return to earth in the bodies of new-born babies. There is, they conclude, no reincarnation as such in African thought. They propose what they call "partial reincarnation" instead - that is, the idea that some characteristics of a dead person are taken up by a baby. The understanding which these scholars have of the concept of reincarnation is, in any case, quite consistent with the meaning implicit in the original Latin conception of reincarnation expressed linguistically as re ("again") and incanare ("to enter into the body") (Onyewuenyi 1996, 16). However, in my encounter with Akan thinkers and culture, I have come across beliefs and ideas that call to question the position of Idowu and Mbiti (I explain why shortly).

In Akan language, there is no single word to describe belief in reincarnation, even though many Akan speakers would admit its presence in their culture. One of my discussants mentioned ako asan aba to describe the phenomenon of reincarnation. ${ }^{3}$ This expression means "having gone and come again". In a similar vein, a person who

\footnotetext{
${ }^{3}$ Interview with Opanin Ado of Kumasi.
} 


\section{H.M. Majeed}

is believed to have returned to earth after his or her death may be called ababio ("one who has returned"). In this regard, someone who is believed to have returned is said to have ba bio ("come again"). In relation to Idowu and Mbiti, though, one can anticipate that both of them would reject the idea that a living-dead can ba bio.

Nevertheless, in some Akan conceptions, the appearance of characteristics of a livingdead in a child seems not to be viewed as "partial" but somehow full reincarnation, although belief in the continuous existence of the living-dead in the spiritual realm is still held. There is, apparently, belief in reincarnation in Akan thought, although Idowu and Mbiti would be correct in observing that such a belief is inconsistent with the idea of the permanent existence of the living-dead in the spiritual realm. An Akan male adult cited to me the case of his own son whom he believed to be a reincarnation of his father (the son's grandfather). ${ }^{4}$ The son, among other forms of behaviour, looks after his father's (the discussant's) interests and sometimes speaks to him with the authority which a father has over his son. This, the discussant believed, was an indication of the rebirth of his father.

Another reason why Idowu and Mbiti's denial of belief in reincarnation may be incorrect is the Akan belief that people who die prematurely, especially those who are in the process of doing good things - things that will change the fortunes of the family for the better, but die before the completion of those activities or projects - may come back. This is in spite of the fact that such people may not be quite old at all.

Nevertheless, belief in reincarnation in Akan thought differs from those found in other cultures, especially in non-African cultures such as the Indian one. ${ }^{5}$ For instance, P.T. Raju (1971, 52-53) argues that the belief which is held in Indian thought that a moral agent must enjoy or suffer the consequences of his or her actions is the basis for reincarnation in that culture. This point suggests that ordinarily, so far as one acts morally or immorally in this world, one would need to return to this world after one's death in the manner determined by the consequences of one's actions in one's

\footnotetext{
${ }^{4}$ Interview with Opanin Kofi Agyei of Nhyeayeso.

${ }^{5}$ Speaking of the culture of the Indians (as a people) is not to suggest that there is a monolithic religious tradition in India. However, what is about to be attributed to India in this paragraph is largely true of all of them.
} 
previous life. This is a simplified meaning of the doctrine of karma. In Akan philosophy, however, many people (moral agents) such as those who do not become part of the (revered) living-dead or do not die prematurely will never experience reincarnation. In this sense, while in Indian thought reincarnation is, generally, a required experience for every human being, it is neither necessary nor open to every Akan.

In Akan thought, with regard to those who are believed to be returned living-dead or to have died prematurely, it seems that reincarnation is conceived of as a good way of making sense of both the death and whole life of the deceased. It is meant, respectively, to provide for the continuous enjoyment of some forms of goodness exhibited in the past and for the completion of life (on earth) as sanctioned by God. It is not necessarily meant, therefore, to provide an opportunity for a morally bad person to become virtuous in the next life. This is why one must look carefully at Sheikh Luqman Jimoh's comment that "One reason advanced by some sections of African people to justify the need for reincarnation is that it affords the deceased another opportunity to right his wrong thereby improving the world of the living" (Jimoh 2012, 92). Given that he does not explain further what he means by "right his wrong", one cannot be sure whether his observation is true of the Akan. If by "right his wrong" he implies an opportunity for each "reincarnated" person to correct his or her bad ways, his observation is not applicable to the Akan people. Indeed, it is quite difficult to attribute to the Akan this notion of "right his wrong" given, also, that dying prematurely, for instance in the middle of changing the lot of one's family, cannot be regarded as a wrong act that requires to be made right. What appears to be bad here is the time of death, which the deceased is not expected to have determined. With regard to the living-dead, the question of "righting" their "wrongs" does not quite arise because they are believed to have generally lived morally good lives, and are as such good people already.

Reincarnation is only possible after one goes through death. Consequently, it would be appropriate to make a few comments about death in Akan thought. Death is believed to be caused by God (Nyame). But the idea that God performs this activity raises questions in the mind of Offiong Asuquo. He observes: 
The problem with this view is that it does not explain whether it is God who causes premature and undesirable deaths such as those caused by suicide, violence, accidents and drowning. Moreover, will God deliberately inflict such pains and sorrows that death often brings when He is seen as a loving father? (Asuquo 2011, 174).

In Akan thought, God is believed to take away the life of a human being at old age, however conceived. ${ }^{6}$ This is why a person who dies prematurely, say in his or her youthful days, would be deemed not to have died "naturally";" the suspicion, sometimes, being that such a person was killed through spiritual means by some other human(s). Such a cause of death is considered especially when, as Gyekye $(1995,80)$ notes about some other deaths, the empirical causes identified are not seen as adequate. Nevertheless, there are unnatural deaths that are regarded as bad: selfinflicted deaths (all forms of suicide) and deaths that occur through accidents and violence are regarded as bad deaths (atôfowuo) that are not caused by God. Bad deaths also include ones that occur through lightning, contrary to Mbiti's thinking that they are caused by God (Mbiti 1989, 151). Besides, if a tree should fall on a person, his or her death would be regarded as bad. This sort of death is correctly described by Gyekye as not traceable to God, adding that it could be caused by "any of the lesser spirits or ancestral spirits" (Gyekye 1995, 78). Furthermore, since these deities and the living-dead are believed to kill often as punishment, some Akan thinkers suggest that those who suffer deaths caused by these beings or, generally, die bad deaths will not reincarnate. However, there does not seem to me to be any really strong reason why such people should not reincarnate, given at least that they are yet to complete their terms of life. Some Akan thinkers, nonetheless, entertain the idea that some such people can also reincarnate. ${ }^{8}$

Concerning Asuquo's question as to why a loving God would "deliberately inflict pains and sorrows" on human beings through death (Asuquo 2011, 174), it may be admitted that it is, indeed, painful to lose a human being, especially if he or she is good or close to us. In some sense, Asuquo's question appears to touch on the

\footnotetext{
${ }^{6}$ Although it is difficult to put numbers to the idea of old age, some philosophers have attempted to do so. Kwame Gyekye states that there is talk of old age when people live "at least into their fifties" (Gyekye 1996, 163).

${ }^{7}$ By "natural" I mean consistent with the original means and time of death sanctioned by God (Nyame).

${ }^{8}$ Nana Kwaku Manu of Abrepo is an example.
} 
problem of inconsistency in divine attributes. However, since this question is posed partly in an effort to understand the conception of death in the African culture, it would be appropriate to interrogate the question of death further.

The physical occurrence of death is painful to the living because, first, someone who is dear to them can no more be seen, found or reached (at least, directly). In another breath, the pain felt by the living is sometimes caused by their inability to come to the aid of the departing person, that is, to prevent his or her death. Mbiti puts it thus:

..., death is a monster before whom man is utterly helpless. Relatives watch a person die, and they cannot help him escape death. It is an individual affair in which nobody else can interfere or intervene. This is the height of death's agonies and pain, for which there is neither cure nor escape, as far as African concepts and religions are concerned (Mbiti 1989, 154).

Mbiti's position has to be carefully examined in connection with how he conceives the causes of death in African thought. He identifies the following as the causes of death: magic, human fore-acceptance of death (as expressed in myths), sorcery, witchcraft, the living-dead and other spirits (Mbiti 1989, 151), and makes the following remarks:

Even when God may be seen as the ultimate cause of death, other intermediary agents may be brought into the picture to satisfy people's suspicions and provide a scapegoat ... This means that, although death is acknowledged as having come into the world and remained there ever since, it is unnatural and preventable on the personal level because it is always caused by another agent. If that agent did not cause it, then the individual would not die. Such is the logic and such is the philosophy concerning the immediate functioning of death among human beings (Mbiti 1989, 151-152).

The idea that death is "unnatural" and "always caused by another agent" (at the personal level) seems to proceed from the assumption that African thinkers always trace the immediate cause of death to fellow humans, except that they would, in the final analysis, suggest that God caused that death. However, this is not the case in Akan thought. For, at least, people who die at old age and not in a "bad" way are deemed, even in the immediate sense, to have died naturally and by the act of God. It is also not the case that such deaths are "preventable". Besides, the danger in 


\section{H.M. Majeed}

classifying all deaths as immediately unnatural is that it may be misunderstood by some to constitute grounds for the human being's difficulty in coming to terms with the phenomenon of death. However, the idea of the unnaturalness of all deaths is not supported, at least in Akan thought.

Nevertheless, an Akan philosopher, J.B. Danquah, also holds the idea of the unnaturalness of death for a different reason. He writes "Death ... is not a natural thing. Basically, there is no reason why any man, any being, should die, barring accidents, and that death which overtakes us, as we say, in the natural course of life, is not evidence that life is spent, but evidence that something has gone wrong with some part of the integrated organism" (Danquah 1968, 160). According to him, this is why among Africans the death of a dear one "causes amazement, an inexplicable occurrence for which a visible cause must be found, either witchcraft or poison or neglect or fatal disease" (Danquah 1968, 160-161). It is quite strange, however, why the cause of an amazing and inexplicable event should be visible, assuming Danquah were not mistaken about the nature of such an event. It is rather likely that an event really regarded to be inexplicable in African culture would not be explored or understood with such disregard for metaphysics. It is also questionable that that which can be physically established (such as death by poison, disease or neglect) would be regarded as inexplicable. Such a death might be regarded as strange if it is believed, for instance, that some spirit or spiritual means was used to make someone take a poison, have a fatal disease or neglect a dying person. In this context, the example of witchcraft is acceptable, but it (witchcraft) is not really visible/physical as Danquah portrays it. ${ }^{9}$

Asuquo's statement that God is the cause of death in African thought would make sense to the Akan thinker only within the concept of ultimate cause (as mentioned above by Mbiti). Such a conception is rationalized in various ways. In Akan thought, for example, death caused by God is not only a fulfilment of the destiny of the person

\footnotetext{
${ }^{9}$ In an apparent disagreement with Danquah, Kwesi Dickson, an Akan religionist, suggests that “... the African, interprets his world theologically ... in terms of final rather than material causes" and he or she believes that "disease and death are caused ultimately by spirits" (Dickson 1984, 50). Despite the stated non-physicality of witchcraft, the effects of it may nonetheless be felt physically, meaning that the spiritual world has "the closest possible relationship with the material world" (Nzeanya 1970, 36). In Akan culture, witchcraft is believed to be a spiritual power that, among other things, can "cause injury to health and property" (Sarpong 1974, 46).
} 
- which his or her soul accepted before coming into this world - but it is also part of the process necessary for the completion of the natural course of human living. ${ }^{10} \mathrm{~A}$ person (onipa) is expected to come into the world through birth, live, die and ultimately end up in the world of invisible beings - either in the land of the revereddead or just as a wandering soul. It would, therefore, appear inconsistent to settle on the realities or modalities of death with God - as a necessary condition for entry into this world and a sufficient condition for a return to the spiritual realm - and turn around to ask why God should help us meet those agreed conditions. Nevertheless, if a person feels now that he or she is no longer comfortable meeting that expectation, that is, going through the pain of death to reach the spiritual realm, would it not be inconsistent to portray a loving God (as done by Asuquo) as the same being who persistently puts humans through pain? ${ }^{11}$ Yet the reality of death facilitated by God and its place in the natural, ontological progression of the human being requires that he or she honourably attempts to come to terms with death and the role it plays in his or her continual survival. In this broader sense of human ontology, then, death and God's causation of death (and its accompanying pain) are understandable to the Akan. Death is regarded as part of the equation of life, in the broader sense. Asuquo acknowledges the transitional function of death, but he does not exhaustively discuss its relevance to the individual in the African context, except to state that the lives of many Africans are "influenced positively" by belief in this function (Asuquo 2011, 174). He then expresses the following view about the living-dead:

The ... point that states that death is a transition which involves a transformation from the physical into the spiritual, as the dead continue to live as ancestors ... is based on beliefs and subjective perceptions like dreams, visions and hallucinations which cannot be independently or scientifically verified (Asuquo 2011, 174).

I am not quite sure that the mere act of hallucinating about a dead person constitutes grounds for belief in personal survival: an illusory perception, in every sense, remains just that. Not even dreams about a dead person lead the Akan to the belief that the former was actually involved in what was dreamt about. For the dead person's involvement to be regarded as credible, it would depend on the nature of the message conveyed, which could be assessed in relation to relevant facts about the deceased and

\footnotetext{
${ }^{10}$ Like the Akan, the Anlo also believe that God (Mawu) is the giver of destiny (Gaba 1973, 79).

${ }^{11}$ Mbiti suggests that God is loving (Mbiti 1970, 33).
} 
the world. Such involvement is, at the secondary level, confirmable by people who are skilled in indigenous metaphysical modes of enquiry. Therefore, belief in the transitional value of death has some empirical and non-empirical dimensions.

\section{Predestination in Akan Thought}

Predestination, as defined above, may be re-stated as the belief that human actions or world events and their outcomes (particularly as they affect human beings) are determined in advance. However, it is worth noting that what is believed to determine things in advance may or may not be God. In Akan thought, the idea that all human actions and experiences are pre-determined - whether by God or otherwise - is absent. Rather, the human being has free will (fa'hodie). An Akan thinker would therefore disagree with Baron d'Holbach's view that from a scientific perspective, the human being is simply a material being who, in accordance with the laws of motion, cannot help being in constant motion, and that the human being has neither free will nor nonmaterial components such as the soul (d'Holbach 2001, Chapters IV, VI, VII). ${ }^{12}$ Furthermore, Akan reincarnation is not a necessary consequence of morality - as it is in Indian thought (Raju 1971, 52-53) - so the human being is not quite subject to morality-driven predestination which is implicit in the Indian concept of karma, as simplified above by P.T. Raju.

However, I do not argue that there is no belief in the concept of human destiny in Akan thought. "Destiny" in the Akan language is nkrabea. ${ }^{13}$ The human soul (okra), prior to its inhabiting of the body, is believed to take a destiny from God regarding the general aspects of the person's life such as his or her occupation, as well as the time and manner of his or her death (Gyekye 1995, 114-115). Nevertheless, this belief is held alongside the conception that the human being is rational and can choose between good (papa) and bad (bōne). Thus the conception of destiny in Akan moral thought is consistent with the doctrine of soft determinism, which is the idea that some things in life are determined, but that these do not include reason. Yet some

\footnotetext{
${ }^{12}$ He even denies that ancient philosophers, including Pythagoras and Plato, conceived of the soul/spirit as "an immaterial substance or one without extent" (Chapter VII, 54). His work was originally published in 1886 .

${ }^{13}$ Find more about nkrabea in H. Majeed (2014).
} 
conceptions of soft determinism are inconsistent with the Akan outlook, as revealed in William James' remarks: "the determinisms, hard and soft alike, suppress [the excitement that should accompany our capacity for moral choice] by their denial that anything is decided here and now, and their dogma that all things were foredoomed and settled long ago" (James 1884, 13; words in square brackets mine).

Soft determinism, as understood by James and outlined in the previous paragraph, takes away the human element in making things happen in this life through deliberate, free human choices. In Akan thought, however, some things, especially moral decisions and how quickly one moves toward one's given profession (or succeeds in that profession) - and for that matter, succeeds in life - are not predetermined. Thus one may be destined to be a successful mason, but if one does not identify one's masonry talent early enough, one's success may be delayed. Some things in life are therefore within human control. Consequently, the human being is encouraged to lead a good moral life and to strive for the betterment of his or her own life here and now, but not to think or behave as if his or her whole life or moral choices are determined.

\section{Reincarnation and Moral Responsibility in Akan Thought}

Even though according to Akan thought not all humans will go through reincarnation, and one's moral actions in the previous life do not necessarily guarantee one's rebirth and status in another life, it is possible to ask whether belief in reincarnation may influence the question of moral responsibility in this thought system. There are instances in which reincarnation may be regarded as good. For example, when it involves a living-dead or some good person who died prematurely while undertaking a project meant for the benefit of the family. I mention family, not society, because reincarnation is a family affair: one can only reincarnate into one's family. As a result of the perceived desirability of this sort of reincarnation, these returned persons are well received when they are "identified". However, is there any connection between reincarnation and moral responsibility, even as we reckon that morality does not always guarantee reincarnation? For instance, can an Akan be held responsible for anything as a result of the cultural belief in reincarnation? Besides, can reincarnation be a reason why a person may want to act morally? An affirmative answer to these 


\section{H.M. Majeed}

questions would, if offered, suggest that reincarnation could influence the conception of moral responsibility in Akan thought.

Although the forms of reincarnation mentioned in the preceding paragraph are deemed to be good, it is not the case that reincarnation is cited by an Akan as the telos of his or her actions. This is in spite of the fact that individuals believed to have reincarnated in the manner described in that paragraph are expected by their family members to behave in an acceptable way (as witnessed about them in their previous lives). This means that while the performance of morally right actions do not necessitate reincarnation, reincarnation is open to people who act morally. ${ }^{14}$ Yet such people do not act or live in expectation of coming back into this world. In this sense, reincarnation does not appear to influence moral behaviour and, for that matter, does not form a basis for the determination of moral responsibility in Akan thought. Later in this article I endeavour to find out whether this attitude toward reincarnation is justifiable.

What then are the reasons why reincarnation is postulated in Akan thought? It seems to me that a key reason for this is the thinking that it ensures some form of justice (fairness) for the deceased and, to some extent, the family of the deceased. Concerning the one who died prematurely, his or her return is believed to enable him or her to live up to the time originally given by Nyame (God) when he or she was about to come into the world for the first time. This way the person gets back the remaining life-time which he or she was not supposed to lose in the previous life. In the same vein, the family gets some restoration in that it will have the member back. The ease with which many Akan thinkers cite the possible return of a family oriented person seems to have an underlying motive which is quite relevant to the point I am making here, namely, the Akan belief that if the alleged reincarnated person was striving in his or her previous life to improve the lot of the family, his or her return would serve to actualize the potential which the family had in his or her previous life.

\footnotetext{
${ }^{14} \mathrm{I}$ do not argue that someone who is incapable of acting morally at all cannot be reincarnated. Nevertheless, the concern of this article is moral agents.
} 
In order to examine further this sense of ensuring fairness with respect to belief in reincarnation, there is need to pay some attention to the (proper) identification of the alleged reincarnated person, as well as the moral worth of his or her actions in his or her returned life. In this regard, there are practical and conceptual problems. The problems start with the identification of the "person", which is sometimes done with the aid of physical traits observed in "that person" in his or her previous life, up to the time of burial. Yet some Akan thinkers admit that it is possible for there to be a reincarnated person who might not be identified (properly). This implies that it is difficult to tell when a moral agent is not reincarnated. When this admission is considered in relation to the generally held moral doctrine that a person ought to be held responsible for his or her actions, one immediately finds some difficulties in ensuring fair punishment and reward.

If the Akan are not in a position to tell whether or not every moral agent is a reincarnated person, it is conceivable that persons thought to be non-reincarnated might really be unidentified reincarnated persons. This possibility of nonidentification logically opens up the Akan concept of reincarnation to a much wider interpretation than is ordinarily conceived; for it means that the Akan are practically unable to fully account for the lives and moral implications of the actions of many reincarnated persons. Another problem is that if a person who died prematurely, such as the family oriented person, reincarnates to continue with his or her past life, achieving successes that he or she was deprived of (for example), then what about the possibility of this same person suffering in his or her returned life the consequences of his or her past evil actions, however minor?

In asking the question at the end of the previous paragraph I do not have in mind the situation in Indian thought, where the level of morality or immorality engaged in by a person in a previous life determines the status (of being) he or she reincarnates into. In Indian philosophy, for instance, a bad person - depending on the level of his or her badness - may come back as a slave (that is, if he or she was already not one), a bird, fish, reptile, or any other lower animal. Without assuming this sort of implication, it is still possible to envisage other forms of punishment if the question posed above were to be addressed in Akan thought - such as remaining a human being but being punished by the family or other persons whom he or she wronged in the past life. Yet 
120 H.M. Majeed

this question is not addressed. It is therefore quite confusing, if not contradictory, to make the continuation of past life - especially for someone whose life got shortened a reason for reincarnation, carrying over to the next life only benefits that are allegedly due to the person, while denying or setting aside the possibility of holding him or her accountable for his or her immoral actions in the previous life. This appears to be selective and contrary to the dictates of the moral and juridical principle held in Akan and, quite possibly, in all other cultural outlooks, that each person ought to be fully held responsible for his or her actions; or that one must reap the fruits of one's actions. It is conceptually flawed to hold this principle while apparently undermining it in the context of reincarnation.

\section{Conclusion}

In this article, I have argued that among the Akan, the revered-dead and people who die prematurely while working toward improving the total well-being of the family are believed to reincarnate, contrary to the view expressed by Idowu (1963) and Mbiti (1989) that belief in reincarnation is nonexistent in African thought. However, while reincarnation is not necessarily dependent on the morality of one's past actions, and while it is also not postulated as a means of ensuring moral responsibility as is the case in Indian philosophy, the notion of moral responsibility is still held on the ground that the individual's moral choices are not determined. Nevertheless, given that the individual may or may not be "reincarnated", and the fact that not all "reincarnated" persons could possibly be identified, I have questioned the ability of the Akan society to ensure that moral responsibility and the principle of fairness are observed. I have therefore inferred that the concepts of reincarnation and moral responsibility cannot be consistently held in Akan philosophy. 


\section{References}

Aurobindo, Sri. 1999. “The Reincarnating Soul”. Christensen, Kit R. ed. Philosophy and Choice: Selected Readings from around the World. Mountain View, CA:

Mayfield, pp.233-237.

Asuquo, Offiong O. 2011. "A Rationalization of an African Concept of Life, Death and the Hereafter". American Journal of Social and Management Studies, Vol.2 No.1, pp.171-175.

Cobo, F.B. 1990. Inca Religion and Customs. Roland Hamilton, Trans. Austin: University of Texas Press.

Danquah, K.A. 1968. The Akan Doctrine of God: A Fragment of Gold Coast Ethics and Religion. Second Edition. London: Routledge.

Descartes, Rene. 1962. "Of Doubt and Certitude". In Singer, Marcus G. and Robert R. Ammerman eds. Introductory Readings in Philosophy. New York: Charles Scribner's, pp.69-80.

D'Holbach, Baron. 2001. The System of Nature. Vol. 1. H.D. Robinson, Trans. Kitchener: Batoche Books.

Dickson, Kwesi A. 1984. Theology in Africa. London: Darton, Longman and Todd.

Gaba, Christian. 1973. Scriptures of an African People: Ritual Utterances of the Anlo. New York: Nok Publishers.

Gyekye, Kwame. 1995. An Essay on African Philosophical Thought: The Akan Conceptual Scheme. Revised Edition. Philadelphia: Temple University Press.

--. 1996. African Cultural Values: An Introduction. Accra: Sankofa.

Idowu, Bolaji E. 1963. Olodumare: God in Yoruba Belief. London: Longman.

James, William. 1884. The Dilemma of Determinism. http://fullonlinebook.com/download-book/book/qpab/the-dilemma-ofdeterminism.pdf

Jimoh, Sheikh L. 2012. "Reincarnation: Re-appraising the Belief of Yoruba Muslims within the Context of Orthodoxy". Ilorin Journal of Religious Studies, Vol.2 No.1, pp.81-96.

Kamath, M.V. 2008. The Philosophy of Life and Death. Mumbai: Jaico Publishing. Kwame, Safro. 2004. "Quasi-Materialism: A Contemporary African Philosophy of Mind". Wiredu, Kwasi ed. A Companion to African Philosophy. Oxford: Blackwell, pp.343-351.

Majeed, H.M. 2014. "The Problem of Destiny in Akan and Yoruba Traditional Thoughts: A Comparative Analysis of the Works of Wiredu, Gyekye and Gbadegesin". Journal of Philosophy and Culture, Vol.5 No.1, pp.43-66.

Mbiti, John S. 1970. Concepts of God in Africa. London: SPCK.

--. 1989. African Religions and Philosophy. Second Revised and Enlarged Edition. Oxford: Heinemann.

Nzeanya, Stephen N. 1970. “God, Spirits and the Spirit World”. Dickson, Kwesi A. and Paul Ellingworth eds. Biblical Revelation and African Beliefs. London: Lutterworth, pp.30-46.

Onyewuenyi, I.C. 1996. African Belief in Reincarnation: A Philosophical Reappraisal. Enugu: Snaap Press. 
Plato. 1977. Phaedo. Grube, G.M.A. Trans. Indianapolis: Hackett Publishing. --. 1945. The Republic. Cornford, F.M. trans. Oxford: Oxford University Press. Raju, P.T. 1971. The Philosophical Traditions of India. London: George Allen \& Urwin.

Sarpong, Peter. 1974. Ghana in Retrospect: Some Aspects of Ghanaian Culture. Tema: Ghana Publishing Corporation.

Wiredu, Kwasi. 1983. “The Akan Concept of Mind”. Ibadan Journal of Humanistic Studies, No.3, October 1983, pp.113-134. 